\title{
THE APPLICATION MODE OF ATHLETES IN THE \\ CALCULATION OF CLOUD MOTION CAPTURE TECHNOLOGY IN FOOTBALL
}

\section{MODO DE APLICACIÓN DE LOS JUGADORES EN EL CÁLCULO DE LA TECNOLOGÍA DE CAPTURA DE MOVIMIENTO EN LA NUBEDE FÚTBOL}

\section{Xin $\mathrm{Hu}^{1}$ (ID \\ (Public Health)}

1. East China Jiaotong University, Jiangxi, Xinyu, 330026,China.

Correspondence:

Jiangxi, Xinyu, 330026,China. yjbhtz@163.com

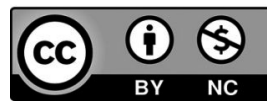

\begin{abstract}
Motion capture is a common problem in sports. It is mainly used to measure and capture running distance in football matches. Use of cloud computing motion capture algorithm in football running distance test, for lack of cloud computing algorithm using motion capture in the application. Data are obtained by experiment to verify the effectiveness and feasibility of the improved cloud computing motion capture algorithm in running distance in football. The final conclusion is that, compared with the original cloud computing motion capture algorithm, the optimized cloud computing motion capture algorithm can significantly reduce the number of cycles in the test of football running distance.
\end{abstract}

Keywords: Cloud Computing; Motion; Algorithms; Soccer; Running.

\section{RESUMO}

A captura de movimento é um problema comum nos esportes. É usado principalmente para medir e capturar a distância de corrida em jogos de futebol. Este estudo aborda o uso do algoritmo de captura de movimento por computação em nuvem no teste de distância de corrida de futebol, por falta do algoritmo de computação em nuvem usando a captura de movimento na aplicação. Os dados são obtidos por experimento para verificar a eficácia e viabilidade do algoritmo melhorado de captura de movimento por computação em nuvem no teste de distância de corrida no futebol. A conclusão final é que, em comparação com o algoritmo original de captura de movimento por computação em nuvem, o algoritmo otimizado de captura de movimento por computação em nuvem pode reduzir significativamente o número de ciclos no teste de distância de corrida no futebol.

Palavras-chave: Computação em Nuvem; Movimento; Algoritmos; Futebol; Corrida.

\section{RESUMEN}

La captura de movimiento es un problema común en los deportes. Es usado principalmente para mediry capturar la distancia de corrida en juegos de fútbol. Este estudio aborda el uso del algoritmo de captura de movimiento por computación en nube en el test de distancia de corrida de fútbol, por falta del algoritmo de computación en nube usando la captura de movimiento en la aplicación. Los datos son obtenidos por experimento para verificar la eficacia y viabilidad del algoritmo mejorado de captura de movimiento por computación en nube en el test de distancia de corrida en el fútbol. La conclusión final es que, en comparación con el algoritmo original de captura de movimiento por computación en nube, el algoritmo optimizado de captura de movimiento por computación en nube puede reducir significativamente el número de ciclos en el test de distancia de corrida en el fútbol.

Palabras clave: Computación en Nube; Movimiento; Algoritmos; Fútbol; Corrida.

\section{INTRODUCTION}

Modern competitive sports are not only the competition between athletes in technology and tactics, but also the competition between countries and the comprehensive national strength, that is, to some extent, the contest of sports science and technology strength between countries. ${ }^{1}$ The modern high-tech, represented by computer information technology and biological gene technology, has penetrated into the whole process of competitive sports, for example, from athlete selection to sports training plan, from exercise load regulation to over recovery after exercise. ${ }^{2}$ Motion capture technology is a new technology based on motion capture system, which can capture and analyze the athletes technical movements, tactical coordination and three-dimensional motion trajectories of moving objects in real time. A motion capture system is a high - tech device used to accurately measure the motion of a moving object in a three-dimensional space. The principle is based on the computer graphics, the arrangement number in the space of the video capture device (tracker), the motion of the moving object is recorded in the form of image, through computer processing, different time units on the spatial coordinates of different objects $(X, Y, Z){ }^{3}$ So it can help coaches and athletes to evaluate the use of technology and 
tactics, but also can monitor the whole process of sports training and competition, and assist decision making in judging decisions. ${ }^{4}$ Motion capture system can capture athletes'movements and facilitate quantitative analysis. It helps people to improve methods combined with the principles of human physiology and physics, so that sports training can get rid of the state of purely relying on experience and enter the state of scientific and digitalization. ${ }^{5}$ In the game, because the velocity of human observation and reaction in the brain can't keep pace with the object, thus missing even referees appear wrongly can hardly be avoided. And the motion capture technology has taken on the referee's job on many occasions. For example, the use of sensors in the Wimbledon open is to analyze whether the ball is out of bounds. It is charged copper sensor coverage a narrow band around the stadium, and then covered with a layer of conductive polymer in the above three areas, these sensors into the stadium (within the boundaries of $5 \mathrm{~cm}, 35 \mathrm{~cm}$ above the boundary and the boundary outside the office); At the same time, there are also conductive materials on the tennis ball used.

\section{METHODOLOGY}

\section{Cloud computing action capture algorithm}

Cloud computing is to make computing distributed on a large number of distributed computers, rather than local computers or remote servers, and the operation of enterprise data centers will be more similar to the Internet. This enables the enterprise to switch the resources to the required applications and access the computer and storage system according to the requirements. "Cloud" has a fairly large scale. Google cloud computing already has about 1000000 servers. Amazon, IBM, Microsoft, Yahoo and so on all has hundreds of thousands of servers. The three people of A.K.Lenstra, H.K.Lenstra and L.Lov.asz first proposed a cloud computing action capture algorithm. The application of cloud computing motion capture algorithm is very extensive, and it cannot be ignored in many fields, such as integer programming, number theory and cryptography. The main function of the cloud computing action capture algorithm is to compute an ORZ decomposition of the upper corner matrix R. After that, on the basis of the traditional motion capture algorithm of cloud computing, Luk and Tracy have studied a new cloud computing action capture algorithm. In the improved algorithm, unlike the same cloud computing action capture algorithm is calculated in the way of DU, instead of calculating R directly to get the decomposition of QRZ. So scholars have a new definition of the reduced basis, in the form of $R$, not in the form of $D$ and $U$ in the past. Here, the columns of the upper triangulation matrix $\mathrm{R}$ are made up of a series of reduced bases, if:

$\left|r_{i i}\right| \geq 2\left|r_{i j}\right|, 1 \leq i \leq j \leq n$,

And

$$
r_{i i}^{2}+r_{i-1, i}^{2} \geq \omega r_{i-1, i-1,}^{2} 2 \leq i \leq n,
$$

In the above formula, $\omega$ is a parameter, and its value is between 0.25 and 1 , which is equal to the reduced basis of the original definition. Because all elements are concentrated together, in the display process, it can also improve the intuition and convenience of observation. Assuming that some $\mid$ and $j$ do not meet the requirements (1), then $\left|r_{i i}\right|<2\left|r_{j}\right|$. Then in the original cloud computing action capture algorithm, set up:

$\gamma=\left|r_{i j}\right| r_{i} \mid$,

In accordance with the equation (3), a single mode array $\mathbf{M}_{i j}$ is constructed and expressed in $\mathrm{R}$.

\begin{tabular}{|c|}
\hline $\mathrm{R} \leftarrow \mathrm{RM}_{i j}$ \\
\hline At the same time, the cumulative transformation $\mathrm{M}_{i j}$ in $\mathrm{Z}$ is: \\
\hline $\mathrm{Z} \leftarrow \mathrm{ZM}_{i j}$ \\
\hline
\end{tabular}

It is verifiable that the $(i, j)$ elements in the new $R$ satisfy the requirements. Then transform (NEwDECREASE $(I, J)$ ), given $R$, calculate $\boldsymbol{\gamma}$ with (3), get $\mathbf{M}_{i j}$ according to (5), and apply $\mathbf{M}_{i j}$ to $\mathrm{R}$, and accumulate $\mathbf{M}_{i j}$ in the matrix $Z$ with initial value as unit matrix. Now, you can define the following transformation and write an improved cloud computing action capture algorithm. A new transformation is given. Given $R, Z$ and $Q, R$ and Z's I-1 column and I column are exchanged, and the plane reflection transformation function in (4) is used to make the column exchanged $\mathrm{R}$ have the upper triangular form, and update $Z$ and $\mathrm{Q}$ :

$\mathrm{R} \leftarrow \mathrm{J}_{i} \mathrm{RII}_{i}, \mathrm{Z} \leftarrow \mathrm{ZII}_{i}, \mathrm{Q} \leftarrow Q J_{i}$

By improving and optimizing the original cloud computing motion capture algorithm, we decompose the QRZ algorithm on the basis of the original $R$ value unchanged, so as to get the new $R, Q$ and $Z$, and the new R column also form a series of reduced basis. Using ball decoding to solve the problem, it is found that the number of enumerated decreases with the increase of the last element of the matrix, so we should pay attention to the high value elements in the bottom of the matrix when changing the matrix.

\section{RESULT ANALYSIS AND DISCUSSION}

\section{Parameter confirmation result}

Based on the algorithm in the above, the actual parameters of the algorithm are confirmed by experiments. In the experiment, combined with the actual situation of running distance test of soccer movement, the number of conditions is set to 10 l with the 20 order square array, of which $i=0,1 \ldots 16$. The way to construct the matrix with the method mentioned in this paper, the A matrix is achieved. Then the A was decomposed by $\mathrm{QR}$, and the experiment was carried out with the obtained $\mathrm{R}$. For the parameter $\omega$, the $0.3,0.5,0.7$, and 0.9 four values are compared. Under each condition, the four values of $\omega$ correspond to the same matrix, so that more objective and reasonable comparison results can be obtained. First, look at the time that the cloud computing action capture algorithm takes. As you can see in Figure 2, as the number of matrix conditions increases, the cloud computing action capture algorithm always takes more time. At the same time, the time consumption is also increased with $\omega$ increase. When the number of matrix conditions is 1016, when the $\omega$ between 0.3 and 0.9 , the difference of the time of consumption is nearly 8 times. Such a result is in line with previous expectations.

At the same time, it can also be used to calculate the number of cycles in the cloud computing motion capture algorithm when different values are taken. Here, when the value of the K changes once in the algorithm, the count of the cycle is added 1. Table 1 is the result of the experiment. It can be seen here that when A takes different conditional numbers, when $\omega$ is 0.9 , the number of cycles is much higher than that of 0.7 . When compared with the value of 0.3 , it achieves 8 times. This is also basically consistent with the above test on the consumption of time. Next look at the nature of the matrix $\mathrm{R}$, and here we use its condition number to determine the quality of the matrix. Figure 3 is the result of the experiment, in which the ordinate $y$ is an exponent. It can be seen that the cloud computing action capture algorithm is better optimized for the number of conditions of the matrix, and the larger $\omega$ is, the more stable the matrix is. At the time of $\omega=$ 0.3 , the properties of the matrix are relatively poor. At the time of taking 0.7 and 0.9 , the number of conditions of the matrix is kept at the same level. So in general, it is a better choice to take a value of about 0.7 . If there is a special requirement for speed or nature, a smaller or larger $\omega$ can be taken.

\section{Algorithm test}

The main section in the last section is to confirm the parameters in the algorithm. The results of the optimized $Q R$ algorithm are tested by numerical experiments. In measuring the running distance of football, 

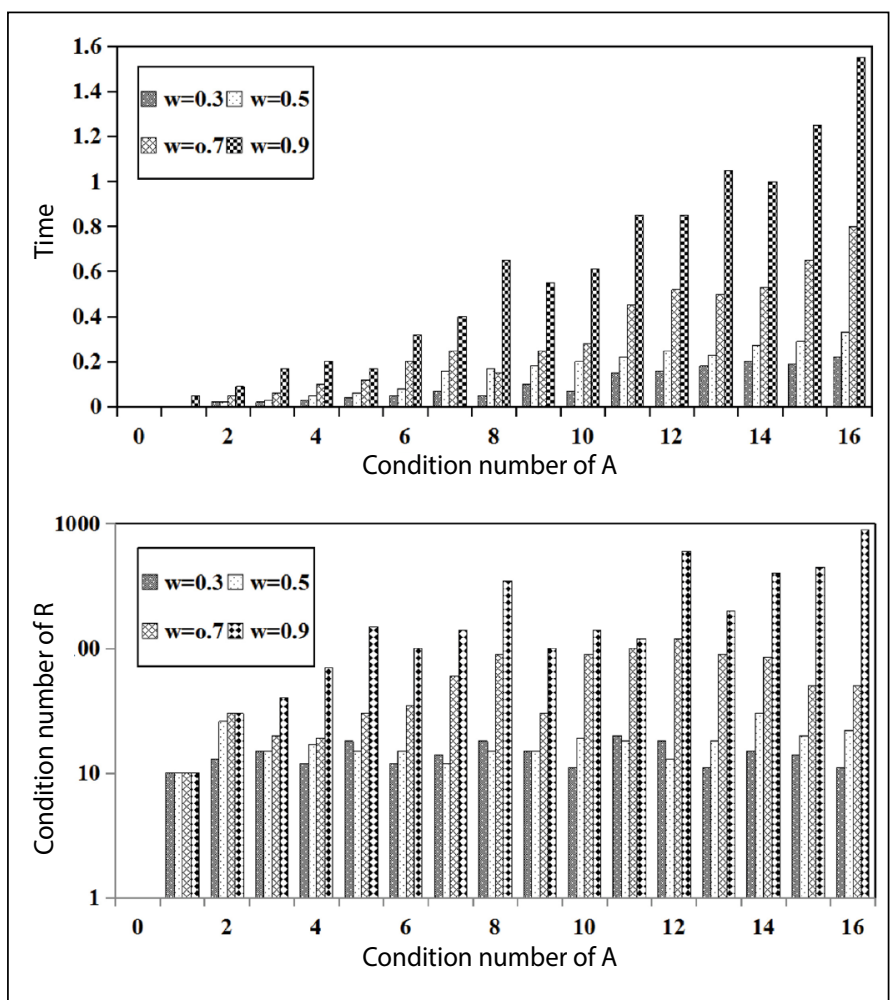

Figure 1. The condition number of the output matrix R when Omega takes different values.

Table 1. The change of the number of cycles in the algorithm with the condition number of $A$ and the change of Omega.

\begin{tabular}{c|c|c|c|c}
\hline Cond (A) & $\boldsymbol{\omega = 0 . 3}$ & $\boldsymbol{\omega = 0 . 5}$ & $\boldsymbol{\omega = 0 . 7}$ & $\boldsymbol{\omega = 0 . 9}$ \\
\hline 101 & 20 & 22 & 35 & 137 \\
\hline 1010 & 187 & 378 & 775 & 1755 \\
\hline 1011 & 197 & 509 & 857 & 1799 \\
\hline 1015 & 255 & 737 & 1073 & 2159 \\
\hline 1014 & 357 & 750 & 1177 & 2253 \\
\hline
\end{tabular}

a matrix of 20 orders can be constructed to show the running route of the athletes, and the number of conditions is set to 10 , of which I $=0$, $1, \ldots, 16$. The way it is built is the same as the previous chapter. The following test, the resulting matrix with two ways to decompose a general QR decomposition, the other is a modified QR decomposition, two equations are obtained, and then optimized the cloud motion capture algorithm of the two equations are decomposed, record the number of times the two equation in circulation in the decomposition process. The determination of the number of cycles can be compared from three aspects. First, in the cloud computing motion capture algorithm built in the paper, observe the number of changes in the recording parameters $k$, which is used to represent the number of cycles, and each change is expressed as " +1 ". Two is two transformations NEWDECRJEASE and EWSWAPRESTORE, and each change is represented as " +1 ". It is worth mentioning that the number of $K$ changes is not always the sum of the two transform counts, because each cycle of $K$ may cause NEWDECREASE to generate multiple transformations. The results of the display are shown in the following Table 2.

Table 2 is the result of the data obtained from this experiment. In the table, the column "old" is used to represent the R obtained by the general QR decomposition, and the "new" represents the R of the modified QR decomposition. By analyzing the tabular data, we can know that the number of calls to NEWSWAPRESTORE transform is significantly reduced under the premise of good external conditions, while the number of calls of NEWDECREASE transformation is not very different, even at some
Table 2. the impact on the number of cycles of the algorithm after the modified QR decomposition under various conditions.

\begin{tabular}{c|c|c|c|c|c|c}
\hline & \multicolumn{2}{|c|}{ K change } & \multicolumn{2}{c|}{ Newdecrease } & \multicolumn{2}{c}{ Newdecrease } \\
\hline condition number & old & new & old & new & old & new \\
\hline 101 & 85 & 20 & 51 & 41 & 34 & 1 \\
\hline 1010 & 102 & 70 & 135 & 156 & 42 & 26 \\
\hline 1011 & 221 & 159 & 240 & 209 & 102 & 71 \\
\hline 1015 & 1370 & 1245 & 1966 & 1870 & 678 & 615 \\
\hline 1014 & 1493 & 1403 & 1984 & 2148 & 740 & 694 \\
\hline
\end{tabular}
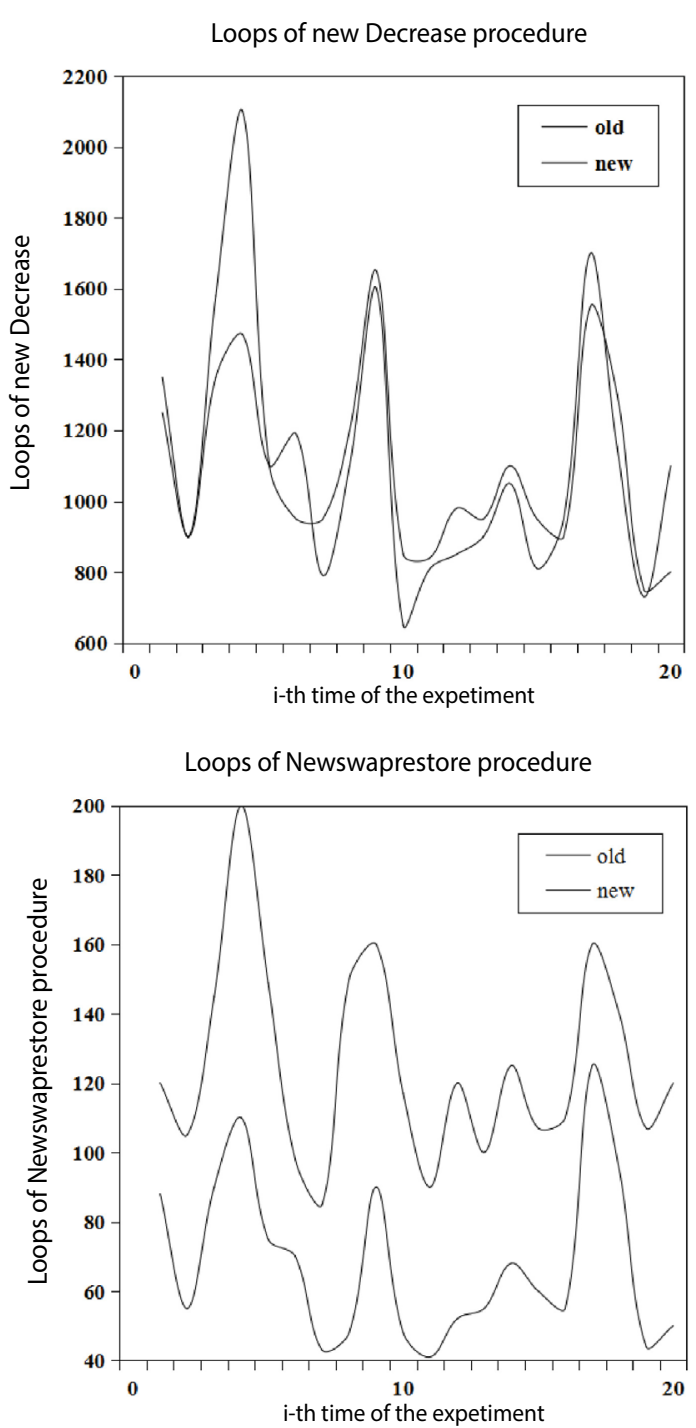

Figure 2. The impact on the number of cycles of the algorithm after the modified QR decomposition is used for a non - ill - conditioned matrix.

time higher than the original frequency. In general, $\mathrm{K}$ has been falling down, which means that the total number of cycles is falling. Under the condition of poor external conditions, the decomposition effect of the modified QR is not obvious, mainly because the number of calls in the NEWDECREASE transformation has not changed significantly, basically maintained at the previous level, and the number of EWSWAPRESTORE transformation has not been significantly optimized. Even when the condition number is 1010, the effect of the general QR algorithm is better than the modified QR decomposition effect. The conclusion obtained in this experiment accords with the expectation. Now ignore the situation of the extreme external conditions, use the 50 order matrix to test the running distance of the football, and directly generate 


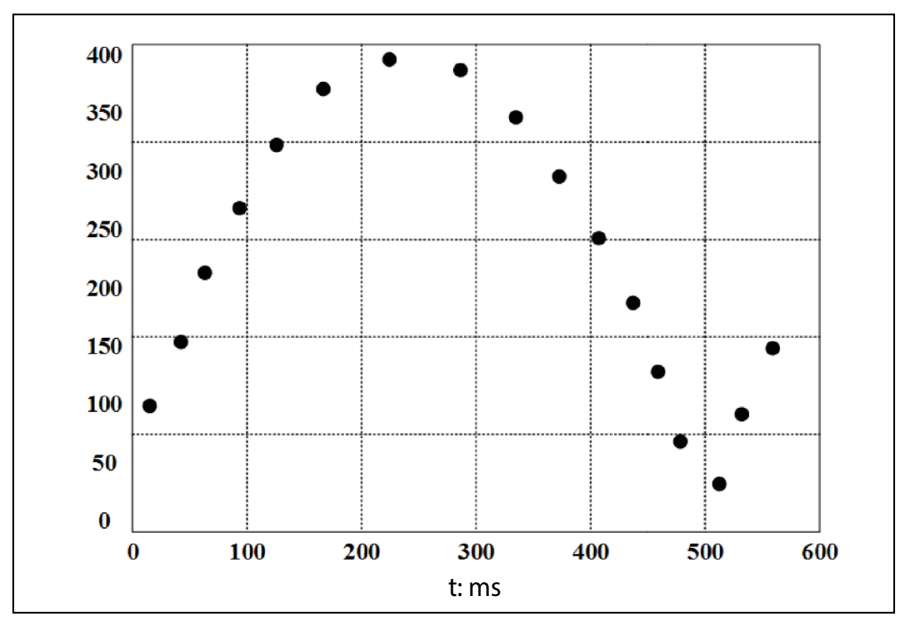

Figure 3. Flight speed estimate.

data with the function RCMD (50) in Matlab, and get the experimental data 20 times repeatedly. By comparing the number of calls of the two transformations of EWDECREASE and NEWSWAPRESTORE, the result of the lower figure 3 can be obtained.

Figure 3 is the result of this experiment. In Figure 3, the left is the comparison of changes in the number of NEWDECREASE calls in the process, the number of NEWSWAPRESTORE in the process of changing a call. Observing two graphs, we can find that the original QR decomposition and modified QR decomposition test has little influence on the number of times in the NEWDECREASE change process, but it has a very significant improvement effect on the number of NEWSWAPRESTORE migration, and greatly reduces the frequency of the call. It can be concluded that in the non-ill conditioned matrix, using the cloud computing motion capture algorithm before, by using the modified QR decomposition algorithm to decompose, it can significantly reduce the cycle rate of cloud computing motion capture algorithm.

\section{CONCLUSION}

Football is an important part of international sports events and is loved by many people. Unlike most sports, football running distance is long and not uniform running, so athletes'running ability directly affects the tactics and achievements of competitions. Therefore, it is urgent to study the running ability of football. In the course of the development of football, computer technology is used in technical and tactical training. Under this background, through the cloud motion capture algorithm to calculate the football running distance, by combining with the actual situation, improvement and optimization of a new cloud motion capture algorithm and OR decomposition optimization, improve the optimization efficiency of the algorithm; improve the purpose of football tactics. In addition, the optimized algorithm is tested to confirm the final parameters and the parameters are imported into the algorithm, and the algorithm is applied to the running distance of football to test, and the conclusion is drawn: Compared with the traditional algorithm, the improved cloud computing motion capture algorithm greatly reduces the number of running cycles, improves the effectiveness and feasibility, and improves the accuracy of the calculation. It has a very important practical significance for the application of football, and is worth publicizing and developing.

The author declare no potential conflict of interest related to this article

AUTHORS' CONTRIBUTIONS: The author has completed the writing of the article or the critical review of its knowledge content. This paper can be used as the final draft of the manuscript. Every author has made an important contribution to this manuscript. Xin Hu: writing and execution.

\section{REFERENCE}

1. Aldous JW, Chrismas BC, Akubat I, Dascombe B, Abt G, Taylor L. Hot and Hypoxic Environments Inhibit Simulated Soccer Performance and Exacerbate Performance Decrements When Combined. Front Physiol. 2015;6:421.

2. Miyasawa Y, Ueno M. Mobile Testing System Optimizing Test Information and Movement Distance. Journal of Biological Chemistry. 2015;273(10):5963-9.

3. Zuo X. Study on the assistant effect of high sugar foods in the long-distance running movement.
Advance Journal of Food Science \& Technology. 2015;8(11):812-5

4. Sparks M, Coetzee B, Gabbett JT. Variations in high-intensity running and fatigue during semi-professional soccer matches. International Journal of Performance Analysis in Sport. 2016;16(1):122-32.

5. Lockie RG, Jalilvand F, Moreno MR, Orjalo AJ, Risso FG, Nimphius S. Yo-yo intermittent recovery test level 2 and its relationship with other typical soccer field tests in female collegiate soccer players. J Strength Cond Res. 2017;31(10):2667-77. 